\title{
Individual Differences in Search for Meaning: The Role of Religion/Spirituality and Social Support-An Indian Perspective
}

\author{
Dr. Shweta Tandon ${ }^{1 *}$, Dr. Seema Mehrotra ${ }^{2}$
}

\section{ABSTRACT}

Background: The diagnosis of cancer can shake the equanimity of the strongest individual and the onset of symptoms and eventual diagnosis are occasions for questions such as "Why me?", "Why now?", and "How did I get this illness?" Aims: The purpose of the present research on a sample of 103 recently diagnosed cancer patients was to investigate the extent of preoccupation with search for meaning, to document individual differences when one is confronted with a cancer diagnosis and to record changes if any in preoccupation during an interval of one month. Secondly to assess the role of religion/spirituality as well as social support in individual encounters with cancer by examining the effects of these two variables among individuals facing a common stressful situation. Lastly to examine relationship of search for meaning with psychological outcomes (anxiety, depression and quality of life). Results: The results indicated that individual differences did exist in the degree of preoccupation with "why me", social support scores significantly differentiated between subgroups with different levels of preoccupation with "why me?" and that patients with highest engagement with "why me" had poorer quality of life and elevated distress levels. Conclusion: Findings highlighted the important role of meaning making issues and the need to address them in intervention. Secondly dialoguing with treating physicians regarding the important role of psychological variables and their relation to distress levels and quality of life.

Keywords: Search for Meaning, Social Support, Religiosity, India

The diagnosis of cancer as Holland (1995) remarked can shake the equanimity of the strongest individual. The diagnosis of cancer brings acute emotional distress (Epping-Jordan et al, 1999, Maunsell , Brisson, \& Deschenes, 1992) and the onset of symptoms and eventual diagnosis are occasions for questions such as “Why me?”, Why now?”, and “How did I get this illness?”.

Thompson and Janigian (1988) have proposed a model (life scheme model) as a way of exploring individual differences in meaningfulness following an extreme stressor. The model

\footnotetext{
${ }^{1}$ Assistant Prof /Sports Psychologist, Sports Injury Centre, Safdarjung Hospital, New Delhi, India

${ }^{2}$ Professor, Dept of Clinical Psychology, Nimhans, Bangalore, India

*Corresponding Author

(C) 2015 I S Tandon, S Mehrotra; licensee IJIP. This is an Open Access Research distributed under the terms of the Creative Commons Attribution License (http://creativecommons.org/licenses/by/2.0), which permits unrestricted use, distribution, and reproduction in any Medium, provided the original work is properly cited.
} 


\section{Individual Differences in Search for Meaning: The Role of Religion/Spirituality and Social Support-An Indian Perspective}

attempts to understand the search for meaning in terms of people's cognitive representations of their lives. The life scheme model suggests several ways in which people may differ in their ability to find meaning after an event such as a cancer diagnosis. Individuals may differ due to their world views, goals and preexisting beliefs. Thompson (1991) has also proposed that the search for meaning could involve any of the three types of attributions-"causal attributions (why do events like this happen), selective incidence attributions (why did this happen to me as opposed to someone else) and responsibility attributions (questions of personal responsibility for the event). The answers to these questions that patients dwell upon and come to hold and accept to varying degrees impact ways patients make meaning of the experience of illness and can be examined in terms of their ability to provide a cognitive framework for coping with the illness (Diefenbach \& Leventhal,1996; Groopman, 2004; Taylor, Kemeny, Reed, Bower \& Grunewald, 2000).

In the present study, the term search for meaning incorporates the degree of preoccupation with the question of "why me?"

Lepore (2001) has theorized that patient's social environment can have a strong influence on their ability to cognitively process their cancer. Supportive others can help individuals work through their stressful memories and make sense of them (Greenberg, 1995). Discussing thoughts and feelings with others can provide an opportunity to confront the "why me" questions and enable individuals to gain insight from others and construct meaning (Redd et al, 2001). Others may provide new perspectives on the illness or its significance, thus either reducing the need to search or may facilitate search for meaning.

Similarly Sigel et al (2001) noted that the pathways through which religious beliefs or activities influence coping with an illness like cancer could be that, religion or spirituality provide an interpretive framework (eg the search for and finding meaning in an event), enhance valuable psychological resources (self-esteem and mastery) or enable easier access to social support and social network integration.

The importance of assessing cancer outcomes not only in terms of patient survival but also in terms of quality of life (QOL) during and following treatment is now well established (DeCosse \& Cennerazzo, 1997; Dunn et al 2003). This perspective has witnessed a proliferation of research activity with the growing recognition that the disease and treatment related biomedical factors do not fully explain the levels of quality of life of individuals with cancer (Montazeri, Gillis \& McEwen, 1996). This entails an examination of a multitude of psychosocial factors in the process of adjustment with cancer and has formed an important focus of psycho-oncology research. 


\section{Individual Differences in Search for Meaning: The Role of Religion/Spirituality and Social Support-An Indian Perspective}

Psychosocial distress in the form of depression and anxiety following the cancer diagnosis has long been identified as a significant issue in patient care. In one of the earliest studies by Derogatis, Morrow and Fetting (1983), it was found that $47 \%$ of ambulatory cancer patients had psychological symptoms sufficient enough to warrant a psychiatric diagnosis. The reported prevalence of diagnosable psychiatric conditions in various studies from India tends to range between $40 \%$ and 80\%, largely mirroring the prevalence data across the globe (Mehrotra, 2008).

Psychological distress may interfere with the adjustment process and alter such physiological parameters as immune functions (Andersen et al, 1998) and the course of the disease (Watson, Havilland, Greer, Davidson, \& Bliss, 1999). It has been established that high level of emotional distress in the context of physical illness adversely affects survival, quality of life, therapeutic compliance, duration of hospitalization and independence in after-care (Fawzy \& Fawzy, 1998; McDaniel, Stephen, Musselman \& Nemeroff, 1997).

The purpose of the present research was to investigate the extent of preoccupation with search for meaning as well as to document individual differences when one is confronted with a cancer diagnosis. Secondly an attempt was also made to record changes if any in preoccupation during an interval of one month. Thirdly to assess the role of religion/spirituality as well as social support in individual encounters with cancer by examining the effects of these two variables among individuals facing a common stressful situation. Lastly to examine relationship of search for meaning with psychological outcomes (anxiety, depression and quality of life).

\section{METHODOLOGY/PROCEDURE}

The present study adopted a single group cross-sectional design along with a short-term followup assessment for a sub-sample of participants. A mixed method approach involving quantitative as well as qualitative components was adopted. Patients included in the study had a confirmed diagnosis of cancer, of which the patient was aware. The information regarding diagnosis was obtained from the consulting oncologist and the patient's awareness regarding the diagnosis was assessed through the caregivers' reports as well as by the researcher at the time of initial contact with the patient while screening. Males and females above 18 years of age, able to understand and speak English or Hindi fluently enough for completion of the study measures., diagnosed to have cancer, within one year of the first contact with the researcher were included in the study sample. Clinically, patients in the active treatment phase, i.e. those who had completed surgery, not more than a about a week ago or were currently undergoing chemotherapy and/ or radiotherapy which was not solely for palliative (symptom relief) purpose but was aimed at disease control formed the study sample.

Patients who were not amenable to assessment due to their physical or cognitive status as adjudged by the researcher during the screening, those who had undergone or were undergoing structured psychotherapeutic intervention for issues related to coping with cancer were not 


\section{Individual Differences in Search for Meaning: The Role of Religion/Spirituality and Social Support-An Indian Perspective}

included in the study. Also clinically, those who were opined to be terminally ill as per the clinical judgments of their consulting oncologists and in whom there had been a recurrence of cancer as per the available medical records were not included in the study.

The final sample constituted of one hundred and three patients. These patients were taken from outpatient and inpatient wings of four hospitals, two general hospitals with oncology units and two hospitals specializing in oncology-care. Across the four settings, the researcher was able to sample participants from a pool of patients who hailed from low, middle as well as upper SES (Socio-econonmic status) backgrounds. Out of the pool of hundred and three patients, thirty patients were recruited for a follow-up assessment approximately one month after the first assessment.

The present study was part of a large research project which was conducted by the researchers exploring psychosocial resources, process of meaning making and psychological outcomes in a heterogeneous group of cancer patients. The present study only utilized variables such as religiosity/spirituality, social support, and search for meaning, distress and quality of life. The assessment as mentioned was conducted at two points (P1 \& P2). At P1, search for meaning, social support, religiousity/spirituality, distress and quality of life measures were administered. This was followed by an open ended interview on the themes related to meaning making. At P2, search for meaning was reassessed.

\section{TOOLS USED}

\section{Basic Data Sheet}

This included details such as name, gender, age, education, marital status, religion, nature of the family (joint/nuclear), occupational status and contact details. The clinical data included diagnosis and stage (filled later by researcher from the medical records), duration since diagnosis, ongoing treatment and treatment if any received in the past.

Religiousity Measure (Blaine \&Crocker, 1995, revised by Exline, Yali \& Sanderson, 2000; Koenig, Parkerson \& Meador, 1997)

For the assessment of religious belief salience, a measure by Blaine and \& Crocker, 1995, revised by Exaline, Yali and \& Sanderson, 2000 was used. The revised religious belief salience measure assesses the extent to which religious beliefs influence one's approach to life. It consists of four items that are rated on a 7- point scale wherein " 1 " indicates "strongly disagree" and "7" indicates "strongly agree". Higher scores on the scale indicate higher salience of religious of religious beliefs in one's life. Cronbach's alpha has been reported to be 0.90 (Exaline, Yali \&Anderson, 2000). 


\section{Individual Differences in Search for Meaning: The Role of Religion/Spirituality and Social Support-An Indian Perspective}

The two items of the Duke's religious index (Koenig, Parkerson \& Meador, 1997) measure have been widely used across cultures to tap the organizational and non-organizational dimension of religiosity. These items refer to social and private and involvement in religious practices respectively and are rated on a six point Likert scale. The authors have reported that in large community and clinical studies, these two items have been related to measures of physical health, mental health and social support. .

Apart from these two measures, the researcher used 3 items with a dichotomous response format to assess whether the respondents considered themselves as being spiritually and/or religiously inclined presence or absence of self reported changes in religious beliefs and practices following cancer diagnoses. The directionality (increase/decrease following cancer diagnosis) of changes, if reported was also enquired.

\section{Assessment of Social Support (Part 2, Pillay \& Rao, 2002) Social support}

Assessment of Social support is a 12-item questionnaire which assesses the perceived availability of social support and has three dimensions-emotional (showing concern, listening), informational (giving suggestion, advice, guidance) and instrumental (physical and financial) support. The respondents were asked to keep in view the support they "generally" perceived as available to them over the years. The items are rated on a Likert scale ranging from 1-5 (1=available none of the time and $5=$ available all the time). Total as well as sub-scale scores may be obtained. Cronbach alpha for the full scale and the test-retest reliability were reported by the authors to be 0.89 and 0.74 respectively. For the present study only 9 items were utilized as the other items were observed to be overlapping. Higher scores reflect higher perceived support.

\section{Meaning Making}

At the first and second point of assessment, meaning-making was assessed through a single item assessing the degree of preoccupation with "why me”. (hardly, sometimes, thought a lot about "why me"). Also at first point, patients were interviewed regarding themes related to search for meaning with the help of open ended questions. Centrality of concern regarding the cancer diagnosis was one such theme. The interviewer also rated the patient's preoccupation with "why

me" based on her impression of patient's spontaneous responses when being interviewed regarding issues related to meaning making during the interview.

\section{Psychological Outcome Measures}

Functional Assessment of Cancer Therapy Scale-General (FACT-G, Cella et al, 1994)-It is a 28 item general cancer quality of life measure for evaluating patients receiving cancer treatment. Data on psychometric properties of the measure are available based on the author's work as well studies from across the globe including India. (Pandey et al. 2005). In the present study, internal consistency of the measure was found to be 0.84 . Higher total scores reflect higher QOL. 


\section{Individual Differences in Search for Meaning: The Role of Religion/Spirituality and Social Support-An Indian Perspective}

Hospital Anxiety and Depression Scale (HADS, Zigmond \& Snaith, 1983)-It is a 14 item scale and assesses the presence and severity of anxiety and depression. This scale is especially suited for assessment of depression and anxiety in the medically ill as it does not contain depression items that might confound with physical symptoms. It has been extensively tested for use in Indian samples and its applicability for use in cancer patients has been documented by Chaturvedi et al (1994).

\section{RESULTS}

The present study findings (Table 1) on the socio-demographic characteristics of the sample revealed that a majority of the sample participants were married and belonged to Hindu religion, had studied up to graduation or above and came from a nuclear family background. However, individuals with education up to PUC (12th) or below were represented by one-third of the sample. Gender distribution revealed that there was a slight over representation of females in the sample. Employed individuals and homemakers had an almost equal representation whereas a minority of participants in the sample was students or unemployed. Approximately $9 \%$ were retirees at the time of the entry to study. An average participant was 49 years old although the sample covered a broad age range from 19 to 79 years. The distribution of age indicated that slightly more than half of the participants were within 36 to $55 \mathrm{yr}$ age range (belonged to the middle adulthood stage) while one third were 56 years or older. A little more than one tenth of the sample belonged to the young adulthood stage, being in the 18-35 years age range.

The clinical data (Table $2 \mathrm{a}$ and $\mathrm{b}$ ) revealed that the mean duration since cancer diagnosis was approximately two months. A little less than half (47.6\%) of the sample was diagnosed within one month of the first contact with the researcher. Individuals more than three months since diagnosis formed approximately one-fourth of the sample. Roughly, one third of the patients (32\%) were diagnosed to have digestive cancer with a majority of them being diagnosed with colon, colorectal or rectal carcinomas. Breast cancer was diagnosed in about a quarter (23\%) of the patients. A majority (67.9\%) were opined to have early stage disease. The distinction between early and advanced was made based on the staging information provided in the medical records and the oncologist's opinion. All the participants were undergoing active treatment. In the single treatment group, there was somewhat an equal representation of patients who had undergone surgery or those who were receiving chemotherapy at the time of assessment. About $20 \%$ of the participants had received /were undergoing more than one modality of treatment at the point of the first assessment.

\section{Individual differences in search for meaning}

Examining individual differences in the process of search for meaning revealed that a substantial number of the participants (38.8\%) reported currently thinking a lot about the question "why me?” indicating a high preoccupation with search for meaning. Roughly thirty percent each 


\section{Individual Differences in Search for Meaning: The Role of Religion/Spirituality and Social Support-An Indian Perspective}

(Table 3) reported that they thought "sometimes" or "hardly "about the issue of "why me?" following cancer diagnosis. (Table 4).

Search for meaning involved understanding the factors that gave rise to it and one such factor was the centrality of concern regarding the health crisis as expressed by the patients. Centrality of concerns herein referred to whether 'having a cancer diagnosis' (being ill with cancer) was in itself the most important current concern in the participants' lives. Half of the participants reported that they were preoccupied with multiple other concerns in their lives rather than with their cancer diagnosis per se. For slightly less than half the sample, "being ill” in itself and other related/unrelated stressors were equally important concerns. Most of these "other” concerns were related to stressors that could be considered to be consequences of the illness. These other concerns were wide ranging and included having children or a family member with a psychiatric diagnosis such as mental retardation, autism and depression, being single parents, recovering from a divorce, having no immediate family, spouse being diagnosed with cancer, being unmarried, having disturbed interpersonal relationships with husband or in-laws, worries about children's wedding and finally about finances. An analysis of concerns in terms of age, revealed that patients who were in the young adulthood (18-35 years) phase were more concerned about their academic and professional goals being stalled whereas those in the middle adulthood (3655 years) had concerns regarding family and financial security. Those who were 56 years and above reported that to a large extent they had fulfilled their duties. However they were concerned about their families especially in terms of being a financial burden. Qualitative analysis of gender differences regarding concerns commonly reported by patients revealed that concerns regarding family and children were expressed by female patients. Most patients were worried as to who would take care of their young children as they had not yet become independent. For male patients, the concerns regarding security for their family were voiced most often, as most of them were the sole bread earners for their family.

Given below is a description of themes that emerged during interviews with participants who reported low, high or modest preoccupation with search for meaning.

\section{Low preoccupation with Search for Meaning:}

It is interesting to note that almost one third of the participants (31\%) reported that they hardly thought about 'why me'. In the interviews, the latter group of patients reported different reasons for not questioning their assumptions about the world when diagnosed with cancer. Some of them reported that "it was the justice of God, we have to accept joys and sorrows in the same spirit" and thus did not search for meaning. They also reported that God had given them this illness and it is He who would help them to recover. Patients also stated that their illness was God's will/plan. For some, having a cancer diagnosis was a like a blessing from God. As one of the patients reported, "God as a shepherd has guided me from the valley of death and he is cleansing the cancer of my soul". Similarly, another patient narrated that he now understood that 


\section{Individual Differences in Search for Meaning: The Role of Religion/Spirituality and Social Support-An Indian Perspective}

"our body is dust, what matters is our soul and I want my soul to go to Jesus. This illness has made me focus on what is important in life and I want to secure a good place up there with God" and therefore there was no need to think about the illness.

There were others who did not think about their illness as they attributed it to their fate. They reported that it was futile thinking and believed that it was their "karma" or a result of their misdeeds in previous births. They reported that they had no choice but "to accept it and take treatment”.

Taking the cancer diagnosis in their stride and trying to have a rather nonchalant attitude towards it, was yet another feature observed in some patients in the subgroup that reported low preoccupation with search for meaning. They reported that since cancer was a disease that could happen to anyone, all they had to do was focus on treatment and have full faith in doctors. As one of the patients reported "I thought that I am not special so why it can't happen to me?"

Finally, for a minority of the patients, other things in their life such as their careers, a spouse being affected by the same illness and being apprehensive about their illness were some of the reasons for their low degree of preoccupation with the question of why I as far as their own diagnosis was concerned.

\section{High preoccupation with Search for meaning:}

Thirty-nine percent patients reported 'thinking a lot about why me', signaling a high level of preoccupation with search for meaning, at the time of first assessment. Qualitative data of these patients revealed that they reported a sense of unfairness at receiving the cancer diagnosis. Majority of the patients expressed that they had not 'harmed' others and thus did not expect God to give them this disease. This group questioned assumptions regarding a just world. They also thought about being a burden on their families as a result of the cancer diagnosis. As one of the patient reported "What have I done to get this illness? I am a burden and I am suffering and everybody is suffering because of me".

In a minority of patients $(\mathrm{n}=5)$ in the high preoccupation with search for meaning subgroup, positive as well as distressing narratives co-existed. As one patient reported, "I thought I am being a burden. I did good to others but Jesus wants me to suffer since he wants my soul to be in peace. Jesus is my doctor and father". Another patient similarly recounted, "Allah has given me this illness as a punishment so that I may go on the right track."

\section{Modest preoccupation with Search for meaning:}

Thirty percent of the patients in the present study 'sometimes' thought about the issue of 'why $m e$ '. The interview narratives of this subgroup were examined to identify the nature of thoughts associated with modest preoccupation with search for meaning. For some patients, being 


\section{Individual Differences in Search for Meaning: The Role of Religion/Spirituality and Social Support-An Indian Perspective}

diagnosed with cancer was due to some sin committed unintentionally and that they had to accept what God gave them. However they also looked at the positive side and reported that since they had faith in God, they were fortunate enough to have been diagnosed early.

Some patients also reported that life was uncertain and that cancer being a disease could happen to anyone and it was just their misfortune to have this disease. Finally, for a few patients, cancer was a disease that affected a part of their body for which they sought treatment and they detached themselves from the cancer experience and hence only sometimes thought about their diagnosis.

\section{Other observations on preoccupation with Search for meaning:}

In addition to documenting the reported preoccupations with the issue of 'why me' in response to a specific question; the researcher also rated the extent to which issues related to why me spontaneously emerged during the interview. Results indicated that interviewer ratings (based on spontaneous narration) tended to somewhat underestimate the extent of preoccupation with/subjective salience of search for meaning. In other words, unless specifically inquired, the patients did not on their own bring up/elaborate on their preoccupation with search for meaning.

Although the above analysis described trends that reflect current level of preoccupation with 'why me'; the results also indicated that the degree of preoccupation was a dynamic process with rather rapid shifts in the very early phase close to diagnosis. Some patients $(n=9)$ reported that they thought a lot about their diagnosis initially but as the treatment was progressing they hardly thought about its implications and focused on treatment. A few also reported a change from 'thinking a lot' to 'sometimes thinking' (6) about their illness and from 'sometimes' to 'hardly thinking' about their diagnosis $(\mathrm{n}=4)$.

Quantitative findings in terms of individual differences (sociodemographic and clinical, Tables $5 \& 6$ ) in the extent of search for meaning indicated that none of the socio-demographic variables had a significant association with levels of preoccupation with why me. Similarly the clinical variables (table $4 \& 5$ ) like the demographic variables did not have a significant association with levels of preoccupation with "why me?".

\section{Changes in degree of preoccupation with why me}

Analyzing further individual differences in search for meaning involved exploring whether these differences persisted when a sub sample of the patients were assessed after a month's interval (P1 To P2).

\section{Changes in preoccupation with Search for meaning}

Eighteen out of the thirty patients (60\%) reported no changes in their degree of preoccupation with 'why me?' from point 1 to point 2 (table 4). Out of this group of eighteen patients, more 


\section{Individual Differences in Search for Meaning: The Role of Religion/Spirituality and Social Support-An Indian Perspective}

than half continued to be either somewhat (2/18) or hardly (10/18) preoccupied with issues of 'why me'. Out of the eighteen patients who did not exhibit changes in preoccupation with search for meaning, one third(6/18) were those who continued to report a high level of preoccupation with meaning making. On the other hand, nine out of the thirty (30\%), patients assessed at both points reported a reduction in preoccupation with search for meaning (from 'thinking a lot' to 'sometimes' or 'hardly about why me'). In another two patients, the level of preoccupation declined from 'thinking sometimes' to 'hardly thinking' about why me. An increase in preoccupation was noticed in only one of the thirty patients (from 'think hardly' to 'think sometimes').

\section{Search for meaning: its role with respect to religion and spirituality and social support}

The third objective of the present study was to examine the role of religion /spirituality as well as social support in the meaning making process particularly in the search for meaning.

In this context when questioned about their inclination towards religiosity and spirituality, approximately $90 \%$ of the participants reported that they were religious. Further on being questioned whether they perceived any differences in religiousity and spirituality, about 87.4\% of the participants reported that for them the two constructs were the same. Preliminary analysis also suggested that the strength of religious beliefs were reportedly maintained in a majority of the participants (63\%) following cancer diagnosis. In fact, almost one third reported a strengthening of their religious beliefs following diagnosis and only $5 \%$ reported a weakening of religious beliefs. Along similar lines, 55\% reported that their religious practices were mostly at the pre-diagnosis level whereas $38 \%$ reported an increase in religious practices. Seven percent reported a decreased engagement in religious practices.

Further examining the relationship between search for meaning and religious belief/practice revealed religious belief and practice scores did not differ significantly across groups with differential levels of preoccupation with "why me" (table 7). Since quantitative findings did not provide significant associations between search for meaning and religious belief and practice scores, qualitative analysis of the interview data was looked into to provide insights. It was revealed that patients reported that "there was a power above that guided them" and that their cancer pain subsided "when they prayed to God". Others reported that faith in God removed fear which was important, as fear blocked recovery and that God had given them this illness and He would help them come out of it. Some patients reported that reading works by Indian philosophers for example being a follower of Basavanna or of Swami Vivekananda and other spiritual leaders helped them in making sense of the illness/accepting the same with some degree of equanimity. This reading highlighted the following point as expressed by one participant: "As individuals, when we grow physically from childhood into adolescence and adults....we remain the same, we do change physically but our life force remains the same, our individuality is not 


\section{Individual Differences in Search for Meaning: The Role of Religion/Spirituality and Social Support-An Indian Perspective}

lost and therefore when we do get an illness, why should we think that it would change us as individuals? We tend to remain and identify ourselves as what we were, before the illness".

However Social support scores significantly differentiated between subgroups with different levels of preoccupation with "why me?". Those who reported, "They hardly thought about "why- me" had lower support scores than the subgroup which reported thinking "sometimes" about why- me. Those who thought sometimes about why- me also differed from those who thought a lot about why- me in terms of social support. The former group of patients reported receiving more support than those who thought a lot about why me (table 7).

Adaptive significance of search of meaning: Association of search for meaning and its association with distress(anxiety and depression) and quality of life.

The present study findings revealed that across the subgroups (with different degrees of preoccupation with "why me?") there were significant associations when outcome measures namely anxiety, depression and QOL were assessed cross- sectionally at point 1(table 8). Further post-hoc analyses (through games Howell as well as step down bonferroni method) revealed differences with respect to these outcome variables. Those who hardly thought about 'why me' had lower levels of depression and anxiety and higher scores on QOL as compared to the subgroup who thought a lot about 'why me'. Also the latter subgroup (highest preoccupation with why me) had lower scores on QOL and elevated scores on both anxiety and depression as compared to the subgroup who reported thinking "sometimes" about why me. In other words, the subgroup of patients that thought a lot about "why me", had elevated scores on anxiety and depression and had poorer scores on quality of life.

\section{DISCUSSION}

One of the first objectives of the study was to explore the extent of preoccupation with search for meaning as well as individual differences in the extent of such preoccupation..The study findings highlighted that for more than half of the participants other concerns currently were more important than having cancer per se. This highlights the role of background stressors which could amplify the level of stress experienced when one was diagnosed with cancer. Similar results have also been reported by Pandey et al (2003) who in a sample of Indian patients, observed that a majority were not concerned about their disease and treatment outcome per se but were more concerned regarding their duty as a parent, about finances, job security and the future of their families. Similarly, in another Indian study, Chaturvedi et al (1996) also reported that the commonest concerns were about the future (64\%), subjective physical evaluation (60\%), finances (56\%), being upset (54\%), communication (54\%), current illness (52\%) and inability to do things (50\%). 


\section{Individual Differences in Search for Meaning: The Role of Religion/Spirituality and Social Support-An Indian Perspective}

Patients are likely to differ in their degree of preoccupation with search for meaning ('why me?)'. Search for meaning has been often treated as a universal issue in adaptation to traumatic events with a relative disregard to individual differences. In the present study, almost two third of the participants reported having thoughts about "why me" at least sometimes following cancer diagnosis. Taylor (1983) in her study of women with breast cancer reported that 95\% of the patients and $63 \%$ of their significant others had made a concerted effort to understand why they had developed cancer. Chowdhry (2004) in a sample of Indian cancer patients has also reported similar results wherein search for causal meaning was a critical issue for $80 \%$ of newly diagnosed cancer patients. However Bale (1996) in a sample of breast cancer patients reported lower levels of preoccupation and observed that only 38\% of the participants asked themselves "why me?”At or near the time of diagnosis.

The present study findings also brought to the fore that not all patients were preoccupied with the question of "why me" to the same extent and that high, medium and low levels of preoccupation existed. Examining individual differences in the process of search for meaning revealed that a substantial number of the participants (38.8\%) reported currently thinking a lot about the question "why me?" indicating a high preoccupation with search for meaning. Roughly thirty percent each reported that they thought "sometimes" or "hardly" about the issue of "why me?". As mentioned in the results, patient reported different reasons for the differences in their degree of preoccupation. Those with a lower degree of preoccupation reported that they felt their illness was god's plan/will or it was their fate/karma whereas others either took the illness in their stride or reported that other issues/concerns were more important in their lives than being preoccupied with their illness. Those with a higher preoccupation reported being angry at god for his sense of justice as well as perceiving the illness as a form of punishment which could be either justified/unjustified (as a punishment from God for some misdeed committed in the past). Research has indicated that a substantial portion of cancer patients view their disease as a punishment for their own failings (Abrams \& Finesinger, 1953; Bard \&Dyk, 1956). Similar results have been obtained by Sorajjakool and Seyle (2005) who reported that theological strategies helped patients to deal with cancer by focusing that God causes cancer for a purpose.

The present study findings also highlighted that preoccupation with "why me" was a dynamic process with shifts from low to high preoccupation or from high to modest preoccupation, highlighting attempts made by patients to make sense of their cancer experience either by some resolution in this search or trying to alleviate distress due to higher preoccupation by shifting to lower preoccupation levels.

Reassessment of a subsample of patients after a month's interval to assess the stability in the process of search for meaning revealed that. Preoccupation with search for meaning remained stable in $60 \%$ of the patients. . On the other hand, there was a decline in preoccupation with 'why me' issue noted in approximately $37 \%$ of the patients. Elevation in the level of preoccupation with search for meaning over this period was a rare occurrence. 


\section{Individual Differences in Search for Meaning: The Role of Religion/Spirituality and Social Support-An Indian Perspective}

Interestingly sociodemographic and clinical variables did not report a significant association with levels of preoccupation with "why me?".It was speculated that cancer being a life threatening illness, a rather universal question, when one was diagnosed with cancer was "why did it happen to me?". This was irrespective of gender, education level or age. Irrespective of the duration since diagnosis as well as stage of illness, 'why me?' was question dwelt upon almost by all participants when confronted with an unexpected and life threatening illness such as cancer in the early phase of adaption. However, it needs to be kept in view that these findings may not be generalizable to other samples wherein there are participants with longer than one year duration since diagnosis.

\section{Religious beliefs/practices and search for meaning}

The study findings regarding the second objective of the study were in partial accordance. Surprisingly quantitative analysis regarding the role of religious beliefs and practices did not provide statistically substantial insights except that for a majority of the patients their religious beliefs and practices remained at the pre-diagnosis levels. However the qualitative data suggested that religious beliefs and practices provided patients with a framework to understand the current crisis. Patients might have conceptualized the diagnosis as part of a larger plan or something that had greater meaning rather than experiencing cancer as a random event. According to Maro (2001), religion can be the final device that people hold onto when they seemingly have no other hope left. Similar results were also reported by Ashing, Padilla, Tejero and Kagawa-Singer (2003) who, in a qualitative study examined the breast cancer experience in Asian American women and reported that a majority of women with breast cancer reported that faith helped them cope with their breast cancer by giving them strength and peace and lessening their fears. Specifically, they depended on prayer to help them deal with the illness. The importance of religiousity in helping patients make sense of their cancer experience has also been reported by O'Connor, Wicker and Germino (1990) in a sample of recently diagnosed cancer patients.

Thus the present study findings reiterate that measurement of religious beliefs salience alone may not provide an accurate picture during the adaptation to a major event such as cancer, and that the content and resilience of these beliefs need to be examined.

\section{Social support and search for meaning}

Social support on the other hand, differentiated between those patients thinking sometimes about "why me" from those who hardly thought about "why me" or those who thought a lot. Findings therefore suggested social support probably provided a buffer from very high level of distressing preoccupation with search for meaning while at the same time facilitating modest engagement with meaning making issues. This inference is based on the observation that this group had higher social support than the group reporting a lack of engagement in meaning making (hardly thought about why me). 


\section{Individual Differences in Search for Meaning: The Role of Religion/Spirituality and Social Support-An Indian Perspective}

Research has also indicated that drawing on one's sources of social support may help individuals remain connected to sources of meaning, such as social relationships Maddi (1967) and Durkheim (1951).Patients who confide their fears and concerns to a loving and supportive spouse or close friend appear to be in a better emotional state and cope more effectively with the illness (Bloom, Stewart, Johnston, Bank, \& Fobair, 2001) .Social support may help individuals find meaning by fostering engagement and emotional expression to others. In turn, expression facilitates further processing of the event and its significance (Bower, Kemeny, Taylor, \& Fahey, 1998) and enables individuals to view an event from a more meaningful perspective.

\section{Search for Meaning and Outcomes}

The level of preoccupation with search for meaning (why me) was significantly associated with all the psychological outcomes namely depression, anxiety and quality of life. It was speculated that thinking a lot about 'why me' involved repetitive and often intrusive thoughts about why the illness had occurred, its possible causes and implications. This ruminative process could have contributed to higher levels of anxiety and depression and poorer quality of life. The study findings suggest that lower engagement in search for meaning did not predict poorer outcomes in terms of QOL, depression and anxiety whereas higher preoccupation predicted poorer outcomes. Thus it highlights that patients who do not engage in search for meaning may not necessarily have poorer outcomes but high and continued preoccupation may be a marker of difficulties in meaning-making resolution, distress and poorer QOL.

Thus the present study systematically examined individual variations in meaning-making variables in terms of extent of engagement in search for meaning. The pattern of findings of the present study suggest that examining meaning related issues in the initial phase of adaptation to cancer has implications for identification of individuals who may be more vulnerable to experience of adverse psychological outcomes.

In conclusion the present study highlighted that search for meaning or the degree of preoccupation with "why me" is a construct that has been theoretically compounded but has never been empirically tested. Individual differences in this degree of preoccupation may be present. It also needs to be mentioned that lower engagement in search for meaning did not predict poorer outcomes whereas higher preoccupation in comparison to modest preoccupation predicted poorer outcomes. The study also highlights the role of meaning-making variables in adaptation during the initial phase following cancer diagnosis. This in turn suggests that there is a need to examine the role of meaning-based intervention- components especially for those who may be experiencing difficulties in resolution of search for meaning. Examining meaning related issues in the initial phase of adaptation to cancer has implications for identification of individuals who may be more vulnerable to experience of adverse psychological outcomes. Also 


\section{Individual Differences in Search for Meaning: The Role of Religion/Spirituality and Social Support-An Indian Perspective}

psychological intervention for this group needs to include components that address such issues in ways that facilitate some resolution of search for meaning.

Secondly the quantitative and qualitative data in the present study suggest that religious belief salience may not by itself be useful for understanding the meaning-making processes and outcomes in the initial phase following cancer diagnosis. Other indices related to religiosity that need to be explored for their utility include attachment to God, religious-strain and the content of religious frameworks that may make religious beliefs more/less resilient to traumatic encounters. However the study findings may be used for reiterating to the health professionals the role of psychosocial variables in impacting quality of life of cancer patients undergoing active treatment and dialoguing regarding potential ways of modifying health delivery systems that make them more sensitive and responsive to the psychological needs of the patients.

Thirdly the study findings point to the possibility that individuals who report other concerns in life to be more important than "being ill per se" are likely to be experiencing background life stressors that add to the overall level of stress experienced. These individuals may benefit from psychological interventions that focus on addressing such background stressors and thereby mitigating the overall levels of stress. Although an attempt was made to elucidate background life stress and concerns, a formal assessment or detailed analysis of these variables was not feasible. Very few studies on adaptation to cancer diagnosis rigorously take in account the background life stressors. Qualitative data obtained in the present study suggests a need for such an approach.

The study had few limitations. Firstly the study was limited to an examination of psychosocial variables in cancer patients undergoing active treatment who were in the initial phase of adaptation. All the findings may not be generalizable to those with recurrence or those receiving palliative treatment or those who are unaware of their cancer diagnosis. Secondly, the accounts of psychosocial resources could have been subjected to biases and may not reflect pre-cancer levels of these variables. Thirdly a cross-sectional design was used for several analyses and the findings require to be replicated across samples using longitudinal designs that permit entertaining more confident causal inferences. The follow-up assessment could not be carried out for the entire sample due to limitations in accessing patients at follow-up. Only one month interval could be used between assessments due to feasibility issues including attrition. Longer follow up interval as well as multiple assessment points would help in further clarifying the stability/ dynamic nature of variables. Such designs would also help in understanding whether short term benefits associated with certain variables remain stable over time. Future studies utilizing longer time-frames need to address the question as to whether the role of psychosocial resources as assessed in the initial phase following diagnosis may vary over time in the illness trajectory Finally in addition to self-reports, the outcomes (anxiety, depression and quality of life) could have been assessed using professional rated measures. 


\section{Individual Differences in Search for Meaning: The Role of Religion/Spirituality and Social Support-An Indian Perspective}

\section{REFERENCES}

Abrams, R.D., \& Finesinger, J.E. (1953).Guilt reactions in patients with cancer. Lancet, 6, 474482.

Andersen, B.L., Farrar, W.B., Golden-Kreutz, D., Kutz, L.A., MacCallum, R., Courtney, M.E., \& Glaser, R. (1998). Stress and immune responses after surgical treatment for regional breast cancer. Journal of the National Cancer Institute, 90 (1), 30-36.

Ashing, K.T., Padilla, G., Tejero, J., \& Kagawa-Singer, M. (2003). Understanding the breast cancer experience of Asian American women. Psycho-Oncology, 12(1) 38-58.

Bale, M.L. (1996). The illness attributions of women with breast cancer. Dissertation Abstracts International: Section B: The Sciences and Engineering, 56(11-B), 6377.

Bard, M., \& Dyk, R.B. (1956). The psychodynamic significance of beliefs regarding the cause of serious illness. Psychoanalysis Review, 43,146 162.

Blaine, B., \& Crocker, J. (1995).Religiousness, race and psychological well being: Exploring social psychological mediators. Personality and Social Psychology Bulletin, 21, 10311041.

Bloom, J. R., Stewart, S. L., Johnston, M., Banks, P., \& Fobair, P. (2001). Sources of support and the physical and mental well-being of young women with breast cancer. Social Science \& Medicine, 1 53(11), 1513-1524.

Bower,J.E., Kemeny, M.E.,Taylor, S.E., Fahey, J.L.(1998).Cognitive processing, discovery of meaning ,CD 4 decline, and AIDS-related mortality among bereaved HIV -seropositive men. Journal of Consulting and Clinical Psychology, 66,979-986.

Cella, D. F. (1994). F.A.C.T. manual: Functional Assessment of Cancer Therapy (FACT) scales. Chicago: Rush-Presbyterian-St. Luke's Medical Center.

Chaturvedi, S.K., Shenoy, A., Prasad, K.M., Senthilnathan, S.M., \&Premlatha, B.S. (1996).Concerns, coping and quality of life in head and neck cancer patients. Supportive Care in Cancer, 4(3), 186-190.

Chowdhry, D. (2004).Search for meaning and meaning making in cancer-An exploratory study. Unpublished dissertation submitted to NIMHANS, Bangalore.

DeCosse ,J., \&Cennerazzo ,W. (1997). Quality-of-life management of patients with colorectal cancer. Cancer Journal for Clinicians, 47, 198-206.

Derogatis ,L.R., Morrow, G.R., \& Fetting ,J.(1983). The prevalence of psychiatric disorders among cancer patients. JAMA ,249,751-757.

Diefenbach, M. A., \& Leventhal, H. (1996). The common-sense model of illness representation: Theoretical and practical considerations. Journal of Social Distress \& the Homeless, 5(1), 11-38.

Dunn, J., Lynch, B., Aitken, J., Leggett, B., Pakenham ,K.,\& Newman, B. (2003). Quality of life and colorectal cancer: A review. Australian and New Zealand Journal of Public Health, 27, 41-53.

Durkheim, E. (1951). Suicide: A study in sociology (J. A.Spaulding \& G.Simpson, Trans.). New York: The Free Press. (Original work published 1897). 


\section{Individual Differences in Search for Meaning: The Role of Religion/Spirituality and Social Support-An Indian Perspective}

Epping-Jordan, J. E., Compas, B. E., Osowiecki, D. M., Oppedisano, G., Gerhardt, C., Primo, K., \& Krag, D. N. (1999). Psychological adjustment in breast cancer: Processes of emotional distress. Health Psychology, 18(4), 315-326.

Exline, J.J., Yali, A.M.,\& Sanderson, W.C.(2000). Guilt, discord, and alienation: the role of religious strain in depression and suicidality.Journal Of Clinical Psychology, 56 (12), 1481-1496.

Fawzy, F.I., \& Fawzy, N.W. (1998).Group therapy in the cancer setting. Journal of Psychosomatic Research, 45,191-200.

Greenberg, M. A. (1995). Cognitive processing of traumas: The role of intrusive thoughts and reappraisals. Journal of Applied Social Psychology, 25, 1262-1296.

Holland, J.C., (1995). Psycho-oncology in the new millennium. International Medical Journal, 2(4), 255-257.

Koenig, H.G., Parkerson, G.R. Jr., \& Meador, K.G. (1997). Religion index for psychiatric research. The American Journal of Psychiatry, 154 (6), 885-856.

Lepore, S. J. (2001). A social-cognitive processing model of emotional adjustment to cancer. In A. Baumeister \& B. L. Andersen (Eds.),Psychosocial interventions for cancer. (pp. 99116). Washington: American Psychological Association.

Maddi, S. R. (1967). The existential neurosis. Journal of Abnormal Psychology, 72, 311-325.

Maro, F. (2001). Stigma and HIV/AIDS in Africa: Setting the operational research agenda. Retrieved July 16, 2003, http:// www.hdnet.org/ Stigma/KC Reports/Stigma and religion.htm

Maunsell, E., Brisson, J., \& Deschenes, L. (1992). Psychological distress after initial treatment of breast cancer. Assessment of potential risk factors. Cancer, 70, 120-125.

McDaniel, J., \& Stephen, E., Musselman, D. L., \& Nemeroff, C.B. (1997). Cancer and depression: Theory and treatment. Psychiatric Annals, 27(5), 360-364.

Mehrota,S.(2008).Psycho-Oncology research in India:Current status and future directions.Journal of the Indian Academy of Applied Psychology,34(1),7-18.

Montazeri, A., Gillis, C.R., \& McEwen ,J.(1996). Measuring quality of life in oncology: is it worthwhile? II. Experiences from the treatment of cancer.European Journal Of Cancer Care, 5 (3), 168-175.

O’Connor, A.P., Wicker, C.A. \& Germino, B.B. (1990).Understanding the cancer patient's search for meaning. Cancer Nursing, 13, 167-175.

Pillay, U., \&Rao, K. (2002). The structure and function of social support in relation to helpseeking behaviour. Family Therapy, 29(3), 153-167. Pandey, M., Latha, P.T., Mathew, A., Ramdas, K., Chaturvedi, S.K., Iype, E.M., \& Nair.K.M. (2003). Concerns and coping strategies in patients with oral cancer: A pilot study. Indian Journal of Surgery, 65(6), 496-499.

Redd, W. H., DuHamel, K. N., Vickberg, S. M. J., Ostroff, J. L., Smith, M. Y., Jacobsen, P. B., \&Manne, S.L. (2001) Long-term adjustment in cancer survivors: Integration of classicalconditioning and cognitive-processing models. In A. Baum, \&B.L. Andersen (Eds.) 
Individual Differences in Search for Meaning: The Role of Religion/Spirituality and Social Support-An Indian Perspective

Psychosocial interventions for cancer (pp. 77-97). Washington, DC: American Psychological Association.

Siegel, K., Anderman, S. J., and Schrimshaw, E. W. (2001). Religion and coping with healthrelated stress. Psychology and Health, 16,631-653.

Sorajjakool, S., \& Seyle, B.L. (2005). Theological strategies, constructing meaning, and coping with breast cancer: A qualitative study. Pastoral Psychology, 54(2), 173-186.

Taylor, S. E., Kemeny, M. E., Reed, G.M., Bower, J. E., \& Gruenewald, T. L. (2000). Psychological resources, positive illusions, and health. American Psychologist, 55(1), 99109.

Taylor, S.E. (1983). Adjustment to threatening events: a theory of cognitive adaptation. American Psychologist, 38, 1161-1173.

Thompson, R. A. (1991). Emotional regulation and emotional development. Educational Psychology Review, 3, 269-307.

Thompson, S.C., \& Janigian, A.S. (1988). Life schemes: A framework for understanding the search for meaning. Journal of Social and Clinical Psychology, 7(2:3), 260-280.

Watson .M ., Haviland , J.S ., Greer, S ., Davidson ,J., \& Bliss, J.M.(1999). Influence of psychological response on survival in breast cancer: A population-based cohort study. Lancet ,354,1331-1336.

Zigmond, A.S., \&Snaith, R.P.(1983).The Hospital Anxiety and Depression Scale.Acta Psychiatrica Scandinivica,67(6),361-370.

Tables

Table 1: Basic socio-demographic characteristics of the overall sample $(\mathrm{N}=103)$

\begin{tabular}{|l|c|c|}
\hline Basic socio-demographic characteristics & Frequency & Percentage \\
\hline Age in years & & \\
\hline $\begin{array}{l}\text { Range=19-79 years } \\
\text { Mean=49.44; SD=13.89 }\end{array}$ & & \\
\hline $18-35$ & 14 & 13.6 \\
\hline $36-55$ & 56 & 54.4 \\
\hline 56 \& above & 33 & 32.0 \\
\hline Gender & & 46.6 \\
\hline Male & 48 & 53.4 \\
\hline Female & 55 & \\
\hline Education levels & & 33.9 \\
\hline PUC( Class XII) or below & 35 & 59.3 \\
\hline Graduation & 61 & 6.8 \\
\hline Post graduation & 7 & \\
\hline
\end{tabular}


Individual Differences in Search for Meaning: The Role of Religion/Spirituality and Social Support-An Indian Perspective

\begin{tabular}{|l|c|c|}
\hline Occupation status & & \\
\hline Employed & 47 & 45.7 \\
\hline Self Employed & 17 & 16.5 \\
\hline Clerical staff & 11 & 10.7 \\
\hline Professional & 11 & 10.7 \\
\hline Skilled/Semi-Skilledworkers & 8 & 7.7 \\
\hline Not employed & & \\
\hline Home maker & 43 & 41.8 \\
\hline Retiree & 9 & 8.7 \\
\hline Student & 2 & 1.9 \\
\hline Unemployed & 2 & 1.9 \\
\hline Marital status & 71 & 68.9 \\
\hline Married & 17 & 16.5 \\
\hline Single & 13 & 12.6 \\
\hline Widowed & 2 & 1.9 \\
\hline Divorced & & 70.8 \\
\hline Religion & 73 & 21.5 \\
\hline Hindu & 22 & 7.7 \\
\hline Muslim & 8 & 72.8 \\
\hline Christian & & 27.2 \\
\hline Family Type & 75 & \\
\hline Nuclear & 28 & \\
\hline \multicolumn{1}{|c|}{ Joint } & & \\
\hline
\end{tabular}

Table 1 depicts the socio-demographic characteristics of the entire patient sample.

Table 2A: Clinical data (I) of the overall sample ( $\mathrm{N}=103)$

\begin{tabular}{|l|c|c|}
\hline Clinical characteristics & Frequency & Percentage \\
\hline Duration since diagnosis (months) & & \\
\hline Range-0.4-12, Mean=2.2, SD=2.5 & & \\
\hline One month or less & 49 & 47.6 \\
\hline More than 1 but $<3$ months & 31 & 30.1 \\
\hline$>3$ months & 23 & 22.3 \\
\hline Stage of illness* & & \\
\hline Early & 70 & 67.9 \\
\hline Advanced & 28 & 27.2 \\
\hline Not Available(NA) & 5 & 4.9 \\
\hline Treatment & & \\
\hline Single & $\mathbf{8 2}$ & $\mathbf{7 9 . 6}$ \\
\hline Surgery only & 32 & 31.1 \\
\hline Chemotherapy only & 38 & 36.8 \\
\hline Radiation only & 12 & 11.7 \\
\hline Multiple & $\mathbf{2 1}$ & $\mathbf{2 0 . 4}$ \\
\hline
\end{tabular}

*Staging information was not available for five participants 
Table 2B: Clinical Data (II) of the overall sample: Cancer sites ( $\mathrm{N}=103)$

\begin{tabular}{|c|c|c|}
\hline Cancer sites* & Frequency & Percentage \\
\hline Digestive & 33 & 32.0 \\
\hline Colon /Colorectal /Rectal & 10 & 9.7 \\
\hline Esophageal & 6 & 5.8 \\
\hline Stomach & 7 & 6.8 \\
\hline Bucco- mucosa & 2 & 1.9 \\
\hline Anal canal & 2 & 1.9 \\
\hline Tonsil & 2 & 1.9 \\
\hline Tongue & 2 & 1.9 \\
\hline Pancreas & 1 & 0.9 \\
\hline Maxilla & 1 & 0.9 \\
\hline Breast & 24 & 23.3 \\
\hline Genitourinary & 14 & 13.6 \\
\hline Ovarian & 4 & 3.8 \\
\hline Cervix & 4 & 3.8 \\
\hline Endometrium & 3 & 2.9 \\
\hline Prostate & 2 & 1.9 \\
\hline Vulva & 1 & 0.9 \\
\hline Muskoskeletal & 3 & 2.9 \\
\hline Haematological & 12 & 11.7 \\
\hline Multiple mylenoma & 3 & 2.9 \\
\hline Non Hodgkin's disease & 3 & 2.9 \\
\hline Hodgkin’s disease & 2 & 1.9 \\
\hline Chronic lymphatic leukemia & 1 & 0.9 \\
\hline Malignant lymphoma & 1 & 0.9 \\
\hline Acute myeloid leukemia & 1 & 0.9 \\
\hline Lymphoblastoma & 1 & 0.9 \\
\hline Other & 17 & 16.5 \\
\hline Lung & 7 & 6.8 \\
\hline Larynx & 5 & 4.8 \\
\hline Brain & 3 & 2.9 \\
\hline Endocrine & 2 & 1.9 \\
\hline
\end{tabular}

* The above classification is based on Abraham, Allegra\& Gulley (2005), Bethesda Handbook of Clinical Oncology 
Individual Differences in Search for Meaning: The Role of Religion/Spirituality and Social Support-An Indian Perspective

Table 3: Extent of current preoccupation with “Why me?”(Search for Meaning)

\begin{tabular}{|l|c|c|}
\hline Patient rated (N=103) & Frequency & Percentage \\
\hline Hardly/do not think & 32 & 31.1 \\
\hline Think sometimes & 31 & 30.1 \\
\hline Think a lot & 40 & 38.8 \\
\hline $\begin{array}{l}\text { Interviewer rated salience of meaning } \\
\text { issues(N=100) }\end{array}$ & & \\
\hline Low & 42 & 42.0 \\
\hline Moderate & 23 & 23.0 \\
\hline High & 35 & 35.0 \\
\hline
\end{tabular}

* Data not available for 3 participants on salience

Table 4: Changes in degree of preoccupation with Search for meaning $(\mathrm{N}=30)$

\begin{tabular}{|l|c|c|}
\hline Degree Of Preoccupation & Frequency & Percentage \\
\hline Remained stable & 6 & 20.0 \\
\hline Thinking a lot about why me & 2 & 7.0 \\
\hline Thinking sometimes about why me & 10 & 33.0 \\
\hline Thinking hardly about why me & \multicolumn{2}{|c|}{} \\
\hline Decreased & 4 & 13.0 \\
\hline Changed from ‘a lot' to ‘sometimes' & 5 & 17.0 \\
\hline Changed from ‘a lot' to 'hardly' & 2 & 7.0 \\
\hline Changed from 'sometimes' to ‘hardly' & \multicolumn{2}{|}{} \\
\hline Increased & 1 & 3.0 \\
\hline Changed from 'hardly' to 'sometimes' & \multicolumn{2}{|l|}{} \\
\hline
\end{tabular}

Table 5: Association between Preoccupation with "Why me" and Socio-demographic variables $(\mathrm{N}=103)$

\begin{tabular}{|c|c|c|c|}
\hline $\begin{array}{l}\text { Socio-demographic } \\
\text { characteristics }\end{array}$ & \multicolumn{3}{|c|}{ Degree of preoccupation with “why me?”(Frequencies) } \\
\hline Education level & Think Hardly & Think sometimes & Think a lot \\
\hline PUC(Class XII) or below & 8 & 9 & 18 \\
\hline Graduation \& above & 24 & 22 & 22 \\
\hline $\begin{array}{l}\text { Chi-square/ } \\
\text { Significance }\end{array}$ & \multicolumn{3}{|c|}{$\begin{array}{c}\chi^{2}=3.65 \\
\text { NS }\end{array}$} \\
\hline \multicolumn{4}{|l|}{ Gender } \\
\hline Male & 19 & 15 & 14 \\
\hline Female & 13 & 16 & 26 \\
\hline $\begin{array}{l}\text { Chi-square/ } \\
\text { Significance }\end{array}$ & \multicolumn{3}{|c|}{$\begin{array}{c}\chi^{2}=4.30 \\
\text { NS }\end{array}$} \\
\hline \multicolumn{4}{|l|}{ Age(yrs) } \\
\hline $18-35$ & 4 & 4 & 6 \\
\hline $36-55$ & 18 & 17 & 21 \\
\hline 56 \& above & 10 & 10 & 13 \\
\hline $\begin{array}{l}\text { Chi-square/ } \\
\text { Significance }\end{array}$ & & $\begin{array}{c}\chi^{2}=0.15 \\
\text { NS }\end{array}$ & \\
\hline
\end{tabular}


Individual Differences in Search for Meaning: The Role of Religion/Spirituality and Social Support-An Indian Perspective

Table 6: Association between preoccupation with "Why me" and clinical variables

\begin{tabular}{|c|c|c|c|}
\hline Clinical variables & \multicolumn{3}{|c|}{ Degree of preoccupation with "why me?"(Frequencies) } \\
\hline $\begin{array}{l}\text { Duration since } \\
\text { diagnosis }(N=103)\end{array}$ & Think Hardly & Think sometimes & Think a lot \\
\hline Less than 1 month & 19 & 13 & 17 \\
\hline \begin{tabular}{|l} 
More than 1 month but \\
less than 3
\end{tabular} & 6 & 14 & 11 \\
\hline More than 3 months & 7 & 4 & 12 \\
\hline Total & 32 & 31 & 40 \\
\hline $\begin{array}{l}\text { Chi-square test } \\
\text { Significance }\end{array}$ & \multicolumn{2}{|c|}{$\chi^{2}=7.45 ; \mathrm{NS}$} & \\
\hline \multicolumn{4}{|l|}{ Stage $(\mathrm{N}=98 *)$} \\
\hline Early & 20 & 22 & 28 \\
\hline Advanced & 9 & 8 & 11 \\
\hline Total & 29 & 30 & 39 \\
\hline
\end{tabular}

* Staging information was not available for five participants

Table 7: Psychosocial Resources in subgroups with varying preoccupation with 'why me' $(\mathrm{N}=103)$

\begin{tabular}{|l|c|c|c|c|c|}
\hline Why me & $\begin{array}{c}\text { Group 1 } \\
\text { Hardly think } \\
\text { N=32 }\end{array}$ & $\begin{array}{c}\text { Group 2 } \\
\text { Think } \\
\text { sometimes } \\
\mathbf{N = 3 1}\end{array}$ & $\begin{array}{c}\text { Group 3 } \\
\text { Think a lot } \\
\text { N=40 }\end{array}$ & $\begin{array}{c}\text { Kruskal- } \\
\text { Wallis } \\
\text { test } \\
\chi^{2^{*}}\end{array}$ & $\begin{array}{c}\text { Significantly } \\
\text { different } \\
\text { groups** }\end{array}$ \\
\hline $\begin{array}{l}\text { Psychosocial } \\
\text { Resources }\end{array}$ & & & & & \\
\hline $\begin{array}{l}\text { Religious } \\
\text { belief }\end{array}$ & $21.69 \pm 4.04$ & $22.10 \pm 4.99$ & $23.00 \pm 4.98$ & $\begin{array}{c}3.01 \\
\text { NS }\end{array}$ & - \\
\hline $\begin{array}{l}\text { Religious } \\
\text { practice }\end{array}$ & $9.00 \pm 2.53$ & $10.29 \pm 1.74$ & $9.93 \pm 1.79$ & $\begin{array}{c}5.19 \\
\mathrm{p}=0.075\end{array}$ & - \\
\hline Social support & $36.45 \pm 8.62$ & $40.84 \pm 6.46$ & $35.62 \pm 8.48$ & $\begin{array}{c}\mathbf{8 . 0 8} \\
\mathrm{p}=0.018\end{array}$ & $1 \& 2,2 \& 3$ \\
\hline
\end{tabular}

Results are presented as Mean \pm SD

*Kruskal Wallis test was followed by Mann Whitney U for between group comparisons for overall significant results.

**In all between group comparisons, significance levels were tested with step down modified bonferroni method 
Individual Differences in Search for Meaning: The Role of Religion/Spirituality and Social Support-An Indian Perspective

Table 8: Anxiety, Depression and Quality of life (QOL) in subgroups with varying levels of preoccupation with “Why me?”(N=103)

\begin{tabular}{|c|c|c|c|c|}
\hline \multirow{2}{*}{\multicolumn{2}{|c|}{$\begin{array}{l}\text { Degree of Preoccupation with } \\
\text { "why me?" }\end{array}$}} & \multicolumn{3}{|c|}{ Outcome variables } \\
\hline & & \multirow[t]{2}{*}{ Anxiety* } & \multirow[t]{2}{*}{ Depression** } & \multirow{2}{*}{ QOL** } \\
\hline & $\mathrm{N}$ & & & \\
\hline $\begin{array}{l}\text { Group } 1 \\
\text { Hardly/Do not } \\
\text { think }\end{array}$ & 32 & $3.09 \pm 3.48$ & $5.63 \pm 4.59$ & $63.06 \pm 10.77$ \\
\hline $\begin{array}{l}\text { Group } 2 \\
\text { Think sometimes }\end{array}$ & 31 & $4.52 \pm 4.15$ & $5.45 \pm 4.84$ & $66.06 \pm 10.00$ \\
\hline $\begin{array}{l}\text { Group } 3 \\
\text { Think a lot }\end{array}$ & 40 & $7.65 \pm 4.73$ & $9.55 \pm 5.17$ & $53.70 \pm 12.41$ \\
\hline $\begin{array}{l}\text { Kruskal Wallis } \\
\text { test/ANOVA } \\
\text { Significance } \\
\end{array}$ & - & $\chi^{2}=18.87 ; p=0.000$ & $\mathbf{F}=\mathbf{8 . 2 0} ; \mathrm{p}=0.001$ & $\mathbf{F}=\mathbf{1 1 . 9 6} ; \mathrm{p}=0.000$ \\
\hline $\begin{array}{l}\text { Significantly } \\
\text { different } \\
\text { groups*** }\end{array}$ & - & $1 \& 3,2 \& 3$ & $1 \& 3,2 \& 3$ & $1 \& 3,2 \& 3$ \\
\hline
\end{tabular}

Results are presented as Mean \pm SD

*Kruskal Wallis test ( followed by Mann Whitney U for between group comparisons for overall significant results).

**One way ANOVA was followed by post hoc comparisons for overall significant results ***In all between group comparisons, significance levels were tested with step down modified bonferroni method and one tailed test of significance was adopted 